\title{
¿Para qué sirve una Constitución?: reflexiones sobre la inclusión constitucional de los pueblos indígenas
}

\author{
Salvador Millaleo Hernández*
}

\begin{abstract}
RESUMEN
La sociología se pregunta cómo funcionan las Constituciones en la sociedad. Niklas Lubmann ha señalado que una de las funciones más relevantes de la Constitución es posibilitar la inclusión de los sujetos en la vida política, mediante la organización pública del poder político, la democracia y los derechos fundamentales. En la dimensión simbólica, el constitucionalismo expande con un discurso de inclusión constitucional esos logros. Sin embargo, estas perspectivas chocan con la subinclusión de los pueblos indígenas en los órdenes constitucionales y revelan las promesas del constitucionalismo como un simbolismo negativo y encubridor. La evolución del derecho constitucional, junto con el derecho internacional, han traído nuevas formas de inclusión mediante derechos colectivos para los pueblos indígenas. Estos dispositivos pueden correr los mismos riesgos del simbolismo negativo de una inclusión simbólica.
\end{abstract}

Sociología constitucional - inclusión constitucional - pueblos indígenas

\author{
What is a Constitution good for? \\ Reflections on the constitutional inclusion of indigenous peoples
}

\begin{abstract}
Sociology asks how constitutions work in society. Niklas Lubmann has pointed out that one of the most important functions of constitution is to enable the inclusion of subjects in political life, through the public organization of political power, democracy and fundamental rights. In the symbolic dimension, as indicated by Smend and Brunkhorst, constitutionalism expands those achievements with a discourse of constitutional inclusion. However, these perspectives clash with the sub-inclusion of indigenous peoples in constitutional orders and reveal the promises of constitutionalism as negative and concealing symbolism. The evolution of constitutional law, together with international law, has brought new forms of inclusion through collective rights for indigenous peoples. These devices can run the same risks, of negative symbolism of symbolic inclusion.
\end{abstract}

Constitutional sociology - constitutional inclusion - indigenous peoples

* Licenciado en Ciencias Jurídicas y Sociales, Universidad de Chile. Dr. Phil., Universidad de Bielefeld, Alemania. Profesor de Derecho, Universidad de Chile. Correo electrónico: millaleosalvador@gmail.com.

Artículo recibido el 30 de enero de 2018 y aceptado para su publicación en este número el 18 de enero de 2019. 
$\mathrm{E}$ ste artículo indagará desde el punto de vista teórico de la sociología jurídica acerca de cómo pueden funcionar las Constituciones como conjuntos de dispositivos de inclusión en la sociedad, en específico en relación con los pueblos indígenas, sujetos tradicionalmente ajenos a la vida política de los estados constitucionales de los que forman parte. Esto requiere preguntarse por los roles o funciones que cumplen las constituciones para la vida social, más allá de la normatividad de sus efectos. En este sentido, revisaremos el papel que juegan los derechos colectivos como dispositivos de acomodación que favorece la inclusión constitucional de los pueblos indígenas.

La perspectiva con que reflexionaremos será una teoría social de la Constitución, sin referirnos a un ordenamiento constitucional en particular. En esta reflexión nos serviremos de la teoría de los sistemas sociales de Niklas Luhmann, la que concibe a la Constitución como un logro evolutivo que persigue la inclusión, por medio de conseguir la interdependencia de las autonomías de la política y del derecho, y de la creación de dispositivos específicos de inclusión constitucional, la democracia y los derechos fundamentales. Esta visión será complementada con las perspectivas de Rudolf Smend acerca de las dimensiones simbólicas de la Constitución como forma de integración de la sociedad, y de Hauke Brunkhorst acerca de la mentalidad inclusiva del constitucionalismo moderno.

Sin embargo, un enorme contraste con las pretensiones inclusivas de los órdenes constitucionales es la persistente subinclusión de los pueblos indígenas. Esta realidad social se ha buscado modificar en las décadas recientes mediante arreglos constitucionales que desarrollan mecanismos de acomodo constitucional para las diferencias étnico-culturales.

Aquí no haremos una descripción específica de las diversas instituciones normativas de dichos mecanismos de acomodo constitucional, ni tampoco realizaremos un análisis comparativo de ellos -aspectos ya bien desarrollados en otros estudios-, sino que nos plantearemos cómo ellos están mudando las estructuras de inclusión y la mentalidad del constitucionalismo.

\section{LA INCLUSIÓN CONSTITUCIONAL Y LAS FUNCIONES SOCIALES DE LA CONSTITUCióN}

Una determinación simple, desde un punto de vista jurídico, de una Constitución la comprende como las normas básicas respecto de la institución y el ejercicio del poder estatal ${ }^{1}$. En el concepto clásico, será una Constitución el orden jurídico que: "se caracterice por la garantía de los derechos fundamentales y por un sistema de poderes separados (o de checks and balances) y que sea aprobada por la nación correspondiente al pueblo como el pouvoir constituant. Solo una Constitución que cubra estas pretensiones puede regir como Constitución legítima" ${ }^{2}$.

\footnotetext{
${ }^{1}$ Biaggini, 2003, p. 53.

${ }^{2}$ Ibid.
} 
Las constituciones están asociadas clásicamente al establecimiento de la estructura de un sistema político. Una Constitución establece un sistema de gobierno, define los poderes y funciones de sus instituciones, provee límites sustantivos a su operación, y regula las relaciones entre las instituciones y los ciudadanos. Son conjuntos de reglas y principios que crean, empoderan y limitan las instituciones del gobierno. El papel más importante de las constituciones es limitar el comportamiento del gobierno, en cuanto las constituciones generan un conjunto de principios y derechos inviolables que constriñen la legislación, y las actividades gubernamentales futuras deben ajustarse a ella. Al limitar el alcance del gobierno, las constituciones hacen posible el gobierno.

De acuerdo con Galligan, otra función que sirven las constituciones es la función simbólica de definir la comunidad política y sus objetivos. Una Constitución funciona como un dispositivo que declara la legitimidad del Estado y establece aspiraciones hacia las que el gobierno puede dirigirlo ${ }^{3}$.

Las constituciones son también expresiones de valores, manifestaciones del poder, dispositivos de coordinación social y convenciones de la sociedad ${ }^{4}$. La Constitución proporciona un conjunto de principios y reglas básicas que permiten una mínima coordinación entre los miembros de una sociedad. También establece los principios fundamentales con los que un Estado está constituido o gobernado.

Estas funciones clásicas que se han atribuido a las constituciones están relacionadas con las funciones que se han atribuido al poder. Carré de Malberg concibe las funciones del Estado como las diversas formas en que se manifiesta la actividad dominadora del Estado, correspondiéndole a los órganos del poder ejercer dichas funciones y que no se pueden confundir con sus cometidos ${ }^{5}$. Carré de Malberg llega así a la distinción de las tres funciones clásicas: legislativa, administrativa y jurisdiccional.

Desde una perspectiva diferente, en una sociología del derecho orientada por la teoría de los sistemas sociales, podemos concebir a las constituciones como articulaciones funcionales internas a los procesos sociales, esto quiere decir que se construyen al interior de ellos, y ya no como disposiciones normativas que se deducen e imponen desde fuera a las estructuras sociopolíticas ${ }^{6}$. De acuerdo con aquella teoría, una de las principales funciones de las constituciones es hacer posible la inclusión social.

Por inclusión social entenderemos aquí el acceso que tienen los sujetos a los logros de la sociedad en la que participan, esto es, la forma en cómo son relevantes los sujetos para la vida social, su comunicación y las expectativas que ella realiza. Luhmann definió inclusión social como la forma en la que se hace referencia a las personas en el contexto de la comunicación, es decir, en cómo - la forma y medida en la que- los sujetos son consideradas relevantes en ella ${ }^{7}$.

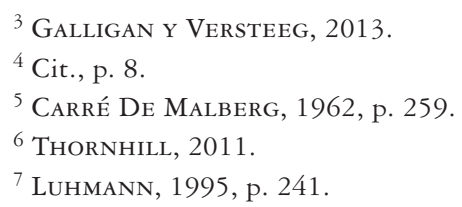


Mediante la constitucionalización del poder político, los procesos de decisión política ganan en inclusividad respecto de los sujetos implicados, en cuanto la formalización del poder permite que este quede abierto procedimentalmente a los diferentes intereses y valores de la sociedad, y no sujeto a un grupo particular, sus intereses y valores ${ }^{8}$. La emergencia de los derechos constitucionales hará posible que la política dé un salto evolutivo en su inclusividad, simplificando y ampliando con ello los contextos en que se ejerce el poder y desarrollando la pluralidad de las formas de vida sociales. La inclusión constitucional no resolverá el conjunto de las exclusiones sociales, pero las hace visibles, como tarea inconclusa del proyecto constitucional.

La inclusividad del constitucionalismo se realiza mediante la creación de esferas comunes para todos los ciudadanos como iguales a la vez que de esferas de diferenciación para que se expresen y desarrollen las identidades de los sujetos que forman parte de la comunidad política 9 . De esa manera, el constitucionalismo implica una compleja interacción entre identidad y diversidad en muchos niveles diferentes ${ }^{10}$.

De acuerdo con la teoría de sistemas sociales de Luhmann, la inclusión social por medio de la Constitución, o inclusión constitucional, se realizaría de dos maneras: primero, gracias a la forma en que las constituciones establecen la interdependencia entre el funcionamiento autónomo de la política y del derecho, organizando un poder público institucionalizado; segundo, por mecanismos específicos de inclusión, a saber, la democracia y sus procedimientos, y los derechos fundamentales.

En primer lugar, este efecto inclusivo de las constituciones se va a producir porque las constituciones establecen un lazo permanente entre las esferas diferenciadas de la política y el derecho en la modernidad. Este vínculo Luhmann lo denomina acoplamiento estructural $^{11}$. Este acoplamiento consiste en una relación permanente de interdependencia, el que no solo no priva a cada uno de esos sistemas que se han diferenciado en la sociedad moderna de su propia lógica o autonomía, sino que permite que se apoyen entre sí para que cada uno logre y fortalezca dicha autonomía ${ }^{12}$. La Constitución permite para el derecho desarrollar un carácter autogenerativo como orden jurídico, produciéndose

\footnotetext{
${ }^{8}$ Morlok, 2014, p. 58.

${ }^{9}$ Rosenfeld, 1994, p. 30.

${ }^{10}$ Ibid., p. 13.
}

${ }^{11}$ Luhmann, 2000, p. 391. El acoplamiento estructural se refiere a la relación de un sistema con las condiciones de su entorno, la que debe darse para poder continuar su autonomía. Cada sistema tiene que adaptarse a su entorno para existir, llevando a cabo sus operaciones de forma autónoma. El acoplamiento estructural es totalmente compatible con la idea de la clausura de los sistemas, porque solo entra en juego en el nivel de las estructuras, de manera que la independencia de los sistemas en la construcción de sus propios elementos y en la determinación de las conexiones, esto es, su clausura, no se ve afectada mientras que al mismo tiempo se observa una coordinación de las estructuras entre el sistema y un otro sistema de su entorno. La Constitución realiza precisamente un acoplamiento estructural permantente entre la política y el derecho. Ver BARALDi et al., 1997, pp. 186-189.

${ }^{12}$ La noción de autonomía de los sistemas sociales Luhmann la identifica con su autopoiesis. Esta se refiere a la característica de un sistema vivo de poseer la capacidad de producir y reproducir los elementos que lo componen, definiendo así su unidad: cada célula es el resultado de la red de operaciones internas del sistema del que es un elemento, no siendo el resultado de una intervención externa. Esta característica 
sus elementos normativos a partir del sistema de fuentes del derecho que organiza principalmente la Constitución; en tanto que, para la política, la Constitución tiene la función de apoyar la autonomía de la política frente a otras fuentes de poder religiosas, económicas y militares, mediante la formalización constitucional del poder político ${ }^{13}$. La política se escapa, mediante su constitucionalización, de su apropiación patrimonial por parte de ciertos grupos con posiciones de poder económicos, religiosas o de otro tipo en desmedro del resto de la sociedad, convirtiendo su poder en un poder público y abstracto.

El derecho puede realizar su autonomía gracias a la Constitución, en la medida en la que dispone con ella de una clausura de sus operaciones dentro de sus propios términos y, por consiguiente, obtiene gracias al desarrollo de la supremacía constitucional un control de sus fuentes formales, componentes y procesos ${ }^{14}$. La Constitución se vuelve el fundamento de todo el derecho, quedando en manos de los propios elementos del derecho la determinación de sus componentes ${ }^{15}$.

Para la política, la Constitución realiza una autolimitación de ella ${ }^{16}$. La política obtiene de la Constitución la posibilidad de usar el derecho de manera instrumental, para implementar decisiones vinculantes, así como de manera no instrumental, para trasmitir valores y fines a la sociedad ${ }^{17}$. El ejercicio del poder mediante el derecho se vuelve más preciso, específico y efectivo. Pero lo fundamental es que, gracias a la Constitución, la política determina la soberanía como un fenómeno puramente político y especifica las formas en las que se realiza como referidas al Estado constitucional. En el Estado constitucional, la voluntad colectiva legítima se produce por medio de una institucionalidad creada por la propia política, organizada y orientada por la Constitución, así como por las reglas dictadas conforme a ella, y no por una instancia de poder externo a la política.

En un segundo lugar, las constituciones tendrán dispositivos específicos de inclusión social. La interdependencia de las autonomías de la política y el derecho, y con ello su desarrollo, no se podrían producir si no existieran diversas formas destinadas explícita y especialmente para lograr la inclusión constitucional.

Primero, la organización democrática del poder hace que este se desenvuelva con procedimientos institucionales y públicos que buscan garantizar que las decisiones de la política queden abiertas a todos los intereses y valores de la sociedad. La determinación democrática de la soberanía que sustenta el constitucionalismo evolucionó como un principio que permitirá a los Estados alejar su poder específico de la interferencia

formulada por Humberto Maturana para los sistemas vivos Niklas Luhmann la observa también en los sistemas sociales. Ver BARALDi et al., 1997, pp. 29 ss.

13 Teubner, 2011.

${ }^{14}$ De Georgi, 1998, p. 119. Mediante la supremacía constitucional, todos los demás componentes del sistema jurídico deben subordinarse a la Constitución, volviéndose disponibles y contingentes ante ella, permitiendo la unidad del sistema gracias al autocontrol que se ejerce de esa manera.

${ }^{15}$ Luhmann, 1990. Sin embargo, la propia Constitución no debe tener a su vez otro fundamento, sino que es autológica, es decir, que se prevé a sí misma como parte del derecho, evitando una escalera infinita de justificación, LuHMann, 1993, p. 471.

\footnotetext{
${ }^{16}$ MORLOK, 2014, p. 54.

${ }^{17}$ Luhmann, 1993, p. 478.
} 
externa de otras formas de poder social, y transmitir ese poder por amplios espacios sociales. La política democrática del Estado constitucional se vuelve un sistema abierto a la contingencia de los cambios sociales, permitiéndole adaptar sus instituciones a ellos.

Segundo, el constitucionalismo garantizará los derechos fundamentales, los que funcionarán para la sociedad permitiendo que ella se desarrolle de acuerdo con la diferenciación en su interior de una creciente pluralidad de formas de vida.

En la visión luhmanniana, los derechos fundamentales de la Constitución realizan la limitación de la intervención del poder político y la igualdad de los ciudadanos, buscando impedir que unas esferas de la sociedad colonicen y subordinen a otras ${ }^{18}$. Los derechos fundamentales representan una protección de la autonomía y aseguramiento de la integridad de cada persona, la que puede combinar sintéticamente en su propia esfera personal los diversos roles que corresponden a su participación en las variadas esferas socialmente diferenciadas ${ }^{19}$. La igual libertad de las personas disuelve las formas sociales de diferenciación por estratificación cerrada, asegurando el libre acceso para todos los sujetos a las diversas arenas funcionalmente diferenciadas de la sociedad. Con ello, la función de los derechos fundamentales no reside en ratificar hechos naturales de los individuos - una cierta naturaleza humana-, sino que en dejar abiertas las posibilidades del desarrollo autónomo de estos en su vida social, evitando cualquier predeterminación ${ }^{20}$, a la vez que permite que la sociedad se desarrolle con la pluralidad de las formas de vida que trae su diferenciación interna.

Desde la perspectiva de la sociedad, La fuerza normativa de los derechos fundamentales responde a la necesidad de la sociedad para que los sistemas sociales funcionalmente diferenciados sean compatibles y para que las lógicas de unos no colonicen las de los otros, dificultando la operación propia de estos ${ }^{21}$. La tarea de compatibilización de los sistemas sociales diferenciados de la sociedad es servida por la Constitución, en el sentido de unidad del sistema jurídico. La constitucionalización del orden jurídico realiza, mediante la supremacía constitucional y de los derechos fundamentales, una integración en los contenidos y procesos de las diversas ramas del derecho, y, por esa vía, de la regulación de las actividades de los diversos sistemas sociales de la sociedad diferenciada.

Las constituciones, a partir de su formulación liberal, se desarrollaron como sets de instituciones que permitirán a las sociedades extraer recursos de poder político distintivo, preservar establemente la especificidad de dicho poder frente a otras clases de poder, y utilizar este poder con una inclusividad creciente. Esta evolución constitucional del poder político permite a la sociedad obrar en un contexto societal cada vez más diferenciado, funcionalmente pluralista y crecientemente positivizado. Adicionalmente, la positividad de las constituciones, es decir, su autocomprensión como grandes convenciones construidas

\footnotetext{
18 Thornhill, 2011, p. 315.

${ }^{19}$ Morlok, 2014, p. 56.

${ }^{20}$ García, 2012, p. 54.

${ }^{21}$ Ibid., pp. 61-62.
} 
por la sociedad y que pueden modificarse según las necesidades de esta, le permitirá a la sociedad enfrentar la variabilidad o contingencia creciente de la organización social.

La constitucionalización hace aparecer en las sociedades modernas un modelo nuevo y generalizado de legitimidad política. Dicha legitimidad dependerá del ejercicio del poder conforme al derecho positivo, la protección y garantía de los derechos constitucionales, y de la naturaleza democrática de las disposiciones constitucionales para la inclusión de los sujetos en la generación de las reglas del sistema jurídico y la toma de decisiones ${ }^{22}$.

El modelo de legitimidad del constitucionalismo, además de los elementos funcionales que describe la teoría de sistemas, contiene elementos simbólicos que lo han definido también como un conjunto de discursos de inclusión constitucional.

Rudolf Smend planteó como la tarea definitoria de la Constitución, la integración de la comunidad política. Con ello intenta capturar el universo simbólico del Estado constitucional moderno ${ }^{23}$. Este universo queda plasmado en los discursos que entienden a las constituciones, a la manera de Thomas Paine, como "gramáticas de la libertad" 24 .

Smend busca considerar el Estado como realidad sociológica, antes que como una realidad estrictamente jurídico-formal, donde existe un conjunto de individuos con una interrelación esencial entre sus miembros ${ }^{25}$. Para Smend, "la integración política es el núcleo esencial y el significado de la Constitución” ${ }^{26}$, en cuanto la función de la Constitución se relaciona con el Estado como encarnación espiritual de la experiencia humana. El Estado se constituye como un orden de vida que implica la vida política del Estado, realizada por la constante y fluida inclusión del individuo. Esta inclusión se produce mediante todo tipo de procesos de vida constitucional. Las diversas manifestaciones de la estatalidad, sus actos individuales, se desenvuelven, se renuevan en la vida conjunta del Estado.

La teoría de Smend propone una distinción entre la integración de los individuos en la vida estatal por medio del liderazgo, de personas o grupos de dominación (integración personal); integración con formas de integración de tipo funcional o procesual que se traducen en formas de vida que tienden a crear un sentido colectivo (integración funcional ${ }^{27}$; la integración como la consecución de objetivos comunes (integración material $)^{28}$.

En específico, la integración funcional trata de "procesos cuyo significado es una síntesis social, que realizan un contenido espiritual en común o fortalecen la experiencia de su comunidad, con la doble acción de una vida intensificada, tanto de la comunidad

${ }^{22}$ Este modelo no podrá surgir sin un desarrollo de la diferenciación funcional de las diversas esferas sociales que se van especializando en el desempeño de ciertas tareas para la reproducción de la sociedad, y sin la distinción moderna entre sociedad e individuo. Vease LuHMANN, 1965.

23 SMEND, 1955.

${ }^{24}$ Citado por MCIlwain, 1947, p. 1.

25 SMEND, 1955, pp. 131-132.

${ }^{26}$ Op. cit., p. 84.

${ }^{27}$ Ibid., p. 148.

${ }^{28}$ Ibid., p. 160. 
como del individuo" ${ }^{29}$. En la integración material, el Estado es una unidad individual, una totalidad que se halla determinada por la concreción de valores sustantivos en situaciones históricas determinadas, valores y fines que no pueden ser externos a él. Estos son consecuencia directa de su naturaleza como agrupación soberana de las voluntades, fines y funcionalidades que le son propios de su realidad social. Estos representan un aspecto determinado, una especificación de la totalidad cultural ${ }^{30}$. Institucionalmente, esa totalidad cultural se reproduce por medio de la representación de los valores históricos que tienen vigencia actual en símbolos políticos en distintos niveles y singularidades.

Lo que Smend llamó la función integ radora de la Constitución cubre la dimensión simbólica de la Constitución. Esta dimensión, en una dimensión positiva -y no en la acepción próxima a la de disfraz de la "Constitución semántica" a la Löwenstein-, corresponde al papel político-ideológico de la Constitución, que por un lado inmuniza al sistema político contra otras alternativas y, por otro, realiza el contraste entre el sentido de las reglas y principios constitucionales y la operación práctica del sistema político. Los problemas constitucionales quedan, en la dimensión simbólica, siempre como una tarea inacabada y pendiente de la Constitución.

La dimensión simbólica de la Constitución encarna el discurso inclusivo del constitucionalismo moderno. Dicho discurso se fue desarrollando vía una evolución que produjo lo que Hauke Brunkhorst ha denominado la "mentalidad del constitucionalismo" 31 . Para Brunkhorst, los logros del constitucionalismo moderno, resumidos en una nueva idea jurídica que se articulada en la noción de la libertad igualitaria, se apodera de las masas durante las revoluciones liberales, transformándose en un nuevo sistema jurídico. Este sistema jurídico inclusivo hará posible la implementación legal de otros sistemas sociales y esferas de valor en la sociedad, de manera que el derecho constitucionalizado se transforma en un "marcapasos de la evolución”, en cuanto el derecho creado por las revoluciones liberales funciona con sus restricciones como una dirección que se da al proceso subsiguiente de adaptación evolutiva ${ }^{32}$.

La constitucionalización surge de la necesidad de resolver el problema funcional básico de una creciente producción de normas legales que se vuelve cada vez más confusa, fragmentada e inconsistente ${ }^{33}$. Pero no solo resuelve este problema funcional con la organización del poder, sino que el constitucionalismo se transforma en la nueva mentalidad de los actores sociales ${ }^{34}$.

La mentalidad del constitucionalismo es un discurso de base kantiana, pues queda definida en la autonomía individual y la autodeterminación pública a la Kant, donde se reconoce públicamente la autonomía de la propia voluntad. En la mentalidad kantiana

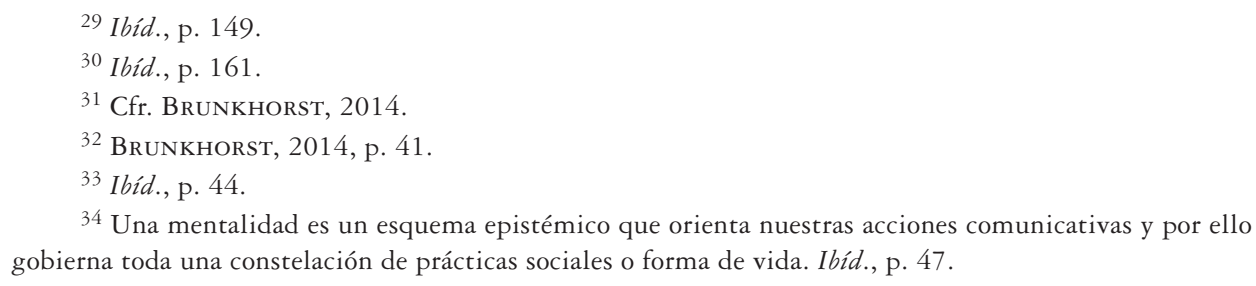

${ }^{34}$ Una mentalidad es un esquema epistémico que orienta nuestras acciones comunicativas y por ello gobierna toda una constelación de prácticas sociales o forma de vida. Ibíd., p. 47. 
del constitucionalismo moderno, la obligación no puede atribuirse a un poder que provenga de un lugar distinto al interior del mismo sujeto ${ }^{35}$.

Por lo anterior, el constitucionalismo tiene una dimensión simbólica donde guarda en su centro los procedimientos democráticos de autodeterminación legislativa, de manera que ninguna norma legal puede existir más allá de los procedimientos legislativos diseñados para expresar la voluntad del pueblo, siendo este último comprendido como el conjunto de todos los destinatarios de una norma. El Estado de derecho constitucional, en la mentalidad kantiana del constitucionalismo moderno, se basa siempre en el consentimiento de los obligados. Dicho consentimiento debe alcanzar siempre a todos los sujetos obligados, en cuanto las constituciones tienen pretensión de ser universalistas en el ámbito personal de validez, "refiriéndose, de forma inclusiva, a todos los miembros de la respectiva organización jurídico-política, atribuyéndoles derechos fundamentales" 36 .

Las revoluciones políticas nordatlánticas del liberalismo llevarán, con diversos vaivenes, a la evolución gradual y sucesiva para implementar el programa de la mentalidad kantiana del constitucionalismo y transformar las constituciones incipientes en un orden constitucional cada vez más comprensivo y más normativo ${ }^{37}$, que portará como su símbolo más destacado el desarrollo creciente de los derechos fundamentales como los dispositivos maestros de inclusión de las sociedades modernas.

\section{LA FUNCIÓN INCLUSIVA DE LA CONSTITUCión FRENTE A LOS PUEBLOS INDÍGENAS}

La evolución del constitucionalismo está marcada en el siglo XX por una expansión de la inclusión constitucional frente a las cuestiones materiales de la vida colectiva, en el sentido de lograr, por medio de fundamentos materiales, que los derechos básicos sean utilizables por todos los sujetos ${ }^{38}$.

Para Dieter Grimm, hay un cambio de enfoque en el derecho constitucional que condujo a la introducción de derechos de participación en el Estado y en la vida socioeconómica y cultural, en tanto que en la disciplina del derecho constitucional se reinterpretará a los derechos básicos desde una visión de derechos para proteger al individuo contra el Estado hacia una visión de ellos como principios para configurar la sociedad ${ }^{39}$.

Dentro de estas transformaciones, la diversidad cultural emerge como un desafío de inclusión para las democracias liberales y el constitucionalismo. Los factores que explican la significación política de la diversidad, Koenig y De GuChteneire ${ }^{40}$, los resumen en i) la globalización que ha hecho que diversos movimientos y grupos sociales reaccionen

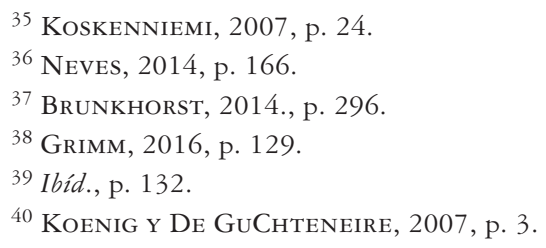


enfatizando su propia identidad; ii) la amplificación de flujos migratorios y diásporas provocados a la vez que posibilitados por el avance de las tecnologías y medios de comunicación y transporte; a ello podemos nosotros agregar iii) la pérdida del rol simbólico del Estado a propósito de su pérdida de poder efectivo ante los poderes globales. Los grupos étnico-culturales demandan una inclusión completa e igualitaria en la sociedad, a la vez que el reconocimiento de sus identidades particulares en la esfera pública ${ }^{41}$. Este reclamo se funda en la crítica del supuesto de la congruencia de la unidad política del Estado y la homogeneidad cultural que caracterizaba al modelo de los Estados-nacionales desde el siglo XIX.

Aquella congruencia fue, en la mayor cantidad de los casos, un supuesto contrafáctico, pues la construcción nacional de los Estados fue acompañada de políticas más o menos violentas de homogeneización cultural y asimilación de las culturas subalternas a las dominantes. Por ello, la demanda de inclusión de grupos subalternos es, a menudo, simbolizada como reclamos de reparación. El ejemplo paradigmático de este fenómeno son los pueblos indígenas en relación con su reconocimiento y protección constitucional en los Estados poscoloniales.

La conquista y colonización de América por parte de los países europeos supuso la puesta en práctica de una trasposición al continente americano de las estructuras sociales, políticas y jurídicas del "antiguo régimen" europeo ${ }^{42}$. Las ordenaciones del dominio colonial se superpusieron, aunque no interfirieron, sino más bien habilitaron la colonización y el colonialismo respecto de los pueblos indígenas ${ }^{43}$. Más allá de las declaraciones protectoras del derecho indiano y otros sistemas normativos coloniales, en la práctica los pueblos indígenas que sobrevivieron a las violencias coloniales y a las ideologías del colonialismo fueron desprovistos de su capacidad de determinación política y quedaron subordinados a la llamada "república de los españoles" ${ }^{4}$.

Las independencias trajeron un momento constituyente del que surgieron los Estados poscoloniales en América. En particular, en América Latina, los Estados sucesores del dominio colonial importaron el modelo constitucional liberal europeo, "donde el único sujeto de las relaciones de poder supraindividuales es el Estado, identificado además con la Nación como términos perfectamente intercambiables" 45 .

La estricta igualdad individual del modelo constitucional en una comunidad política dominada en los hechos por élites criollas mestizas que renegaban de las identidades e instituciones sociales, culturales y políticas de los pueblos indígenas, privará a los indígenas de los beneficios de las independencias. La igualación legal, al considerar

\footnotetext{
41 Ibid.

42 SAntos y Amezúa, 2013, p. 343.

${ }^{43}$ La colonización es el proceso de ocupación y determinación externa de territorios, pueblos, economías y culturas por parte de un poder conquistador que usa medidas militares, políticas, económicas, culturales, religiosas y étnicas, mientras que el colonialismo se referirá a la ideología que legitima el orden asimétrico y hegemónico establecido por el poder colonial. Estermann, 2014, p. 350.

${ }^{44}$ LevagGi, 2001.

45 SANTos y Amezúa, 2013, p. 346.
} 
formalmente a los indígenas como iguales, mientras suprimía las protecciones a sus tierras y los estatutos especiales del derecho indiano, empeoró su situación de hecho, pues perdieron en autonomía y especialmente en el control de sus tierras comunales ${ }^{46}$. A ello se sumaron la proscripción de sus lenguas y el rechazo a sus identidades culturales. Para Castillo Vegas:

"La igualación legal no fue acompañada de las medidas necesarias para hacerla efectiva, lo que se tradujo de hecho en un empeoramiento de la situación de los indios. La igualdad legal no se concretó en una mayor protección jurídica, ni en una mejora económica, ni en una mayor participación política. La autonomía económica y organizativa de las comunidades indígenas será vista, por una parte, como una amenaza a la soberanía de los nuevos Estados independientes -como lo había sido para el absolutismo de la Monarquía borbónica-, pero, por otra, como la principal rémora a la mejora de la actividad económica" ${ }^{47}$.

Dentro de las múltiples exclusiones basados en género, la propiedad y el estrato social, en las fundaciones republicanas constitucionales de las repúblicas oligárquicas en América Latina, la pertenencia indígena seguirá siendo un elemento de exclusión -aunque ahora invisibilizada por su omisión constitucional de la diferencia cultural indígena- de la vida constitucional de los nuevos Estados. La cultura constituyente supondrá las formas de vida indígenas como incivilizadas, bárbaras o salvajes, y ajenas a la vida en común del Estado ${ }^{48}$.

El momento constituyente de las fundaciones republicanas americanas silenciará las diferencias étnico-culturales y asumirán el proyecto de la construcción de una única nacionalidad monocultural, en tanto los nuevos Estados buscarán su consolidación mediante el crecimiento de su poder infraestructural ${ }^{49}$, apropiando para sus élites los recursos de los pueblos indígenas - tierras, fuerza de trabajo, tradiciones reducidas a folklore-, desplegando en este sentido una continuidad del constitucionalismo liberal con las violencias pretendidamente civilizatorias del Estado colonial ${ }^{50}$. El incremento del poder estatal infraestructural significará la integración forzada y asimétrica de los pueblos indígenas en el Estado constitucional de las nuevas repúblicas. Para Raquel Yrigoyen, el horizonte del constitucionalismo liberal en el siglo XIX en América Latina se caracterizará por la sujeción indígena ${ }^{51}$. Esta subordinación se expresará en tres formas de acción del Estado liberal de las élites criollas:

\footnotetext{
46 Castillo, 2013, p. 453.

47 Ibíd., p. 455.

${ }^{48}$ Clavero, 2016, p. 20.
}

${ }^{49}$ El poder infraestructural se refiere a la efectividad del control estatal de su territorio y corresponde la capacidad del Estado para penetrar realmente la sociedad civil, y poner en ejecución logísticamente las decisiones políticas por todo el país. Cfr. ManN, 2007.

${ }^{50}$ Clavero, 2016, p. 23.

51 YRigoYen, 2011. 
“a) asimilar o convertir a los indios en ciudadanos intitulados de derechos individuales, mediante la disolución de los pueblos de indios, tierras colectivas, autoridades propias y fuero indígena, para evitar levantamientos indígenas; b) reducir, civilizar y cristianizar indígenas todavía no colonizados, a quienes las constituciones llamaron "salvajes", para expandir la frontera agrícola; y c) hacer la guerra ofensiva y defensiva a las naciones indias con quienes las coronas habían firmado tratados, y a quienes las constituciones llamaban "bárbaros", para anexar sus territorios al Estado" 52.

La expansión del desarrollo agrícola y agroexportador de los países latinoamericanos en el siglo XIX será a expensas de las formas de vida indígenas, sus valores e intereses, en toda la región ${ }^{53}$. Por otra parte, la generación de los sistemas educativos estatales implicará para los indígenas que el precio por incorporarse al principio de igualdad universal del constitucionalismo liberal será la supresión de su diferencia cultural en las escuelas ${ }^{54}$.

Por cierto, en el proceso de expansión de poder infraestructural del Estado, la construcción de Estados burocráticos que pudieran superar las limitaciones de la situación de partida caracterizada por el carácter patrimonial del Estado colonial tendrá muy diversas fortunas en las repúblicas latinoamericanas y siempre presentará una brecha en relación con los logros de modelo original europeo y nordatlántico.

Las pretensiones de inclusión constitucional quedan silenciadas frente a los pueblos indígenas al negarse, mediante diversas estrategias de asimilación, su existencia en la construcción estatal. La desaparición de los indígenas en el lenguaje constitucional hace imposible su inclusión como tales en los Estados constitucionales. Al no ser un problema constitucional, "la cuestión indígena" se transforma en otras formas de exclusión, en pobreza, ruralidad, falta de acceso a la educación, etc. ${ }^{55}$ Estas formas de exclusión hacen invisibles relativamente a los excluidos para la sociedad, pero la exclusión indígena es reforzada por la asimilación forzada de su diferencia, condenándolos a una próxima desaparición total, mientras sobreviven como campesinos, pobres o menesterosos.

La limitación de la inclusión constitucional mediante la denegación de lo indígena es un caso de "constitucionalización simbólica". Marcelo Neves se refiere a ella en un sentido negativo, al identificar en las periferias de la sociedad global un desarrollo incompleto o inefectivo de la capacidad inclusiva del constitucionalismo y se plasma en una falta de eficacia normativa de los dispositivos constitucionales, especialmente de la función de los derechos fundamentales, que se encubre en el simbolismo del discurso constitucional, la fuerte influencia o colonización de poderes privados, a menudo económicos y culturales, en el Estado, así como la persistencia de las desigualdades sociales ${ }^{56}$.

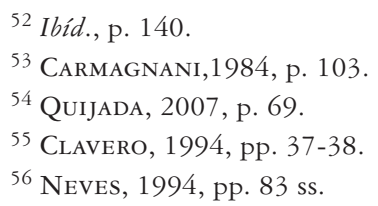


Uno de los rasgos persistentes de la desigualdad en las Américas ha sido precisamente el simbolismo constitucional, en sentido negativo, de aquella forma en que los órdenes constitucionales liberales trataron a los indígenas. Estos gozaban teóricamente de derechos individuales, en tanto, estos no se realizaban debido a que sus identidades culturales eran denegadas como formas de vida inferiores y los recursos materiales que las sustentaban eran apropiados para incrementar el poder de las élites. Esto produce la subinclusión o subciudadanía de los indígenas en un orden constitucional, donde la Constitución, para diversos grupos o sujetos, y muchas veces en un contexto de ineficacia general de las instituciones constitucionales, funcionará más bien como un alibi.

La irrupción del constitucionalismo social en América Latina en el siglo XX, orientado por las necesidades de los órdenes constitucionales de hacer frente a las desigualdades que implicaba la "cuestión social”, significará para los pueblos indígenas la aparición, con diversos tonos, de indigenismos estatales con carácter integracionista -especialmente en países como México y Perú, pero que se difundirá por toda la región hasta su agotamiento en las décadas de los setenta y ochenta del siglo pasado ${ }^{57}$.

Pese a la revalorización de lo indígena que trajeron las políticas estatales indigenistas como elementos formativos de las identidades mestizas que se reivindicaban para los Estados ${ }^{58}$, el integracionismo indigenista no cambiaría la posición subordinada de los pueblos indígenas, en tanto lo que se persiguió fue integrar a los indígenas como individuos a la vida del Estado y al mercado, pero sin romper la identidad monocultural del Estado-nación ${ }^{59}$, ni avanzar hacia recomponer substantivamente los recursos materiales en que se pudiera apoyar la identidad indígena. Es importante destacar que, si bien el indigenismo tuvo un papel significativo en los procesos de construcción nacional de algunos países en el siglo XX, no fue nunca un discurso dominante en la región ${ }^{60}$.

Las políticas indigenistas promoverán el bienestar de los indígenas por medio de un paternalismo estatal, pero sin cambiar su subordinación y procurando su incorporación a la nación mestiza construida por el Estado. Los indígenas no tendrán una participación en las decisiones de las políticas indigenistas y no serán garantizados para ellos derechos que le permitan el control de sus propias formas de vida, ya que las políticas indigenistas serán formuladas por el Estado desde visiones etnocéntricas y que mantenían sesgos estigmatizantes y de supremacía cultural sobre las identidades indígenas ${ }^{61}$. Allí radicaron precisamente las falencias del indigenismo estatal del siglo XX, y que se relacionan con los magros logros de integración individual de sus políticas ${ }^{62}$, de manera que no fueron alterados substantivamente los rasgos de la subintegración social de los pueblos indígenas dentro de los sistemas constitucionales.

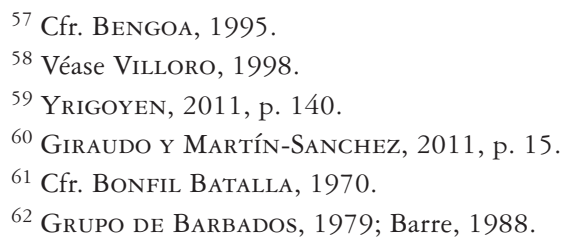


La persistencia de la exclusión de los pueblos indígenas en los ordenamientos constitucionales de las comunidades políticas a las que pertenecen, implica para los indígenas, en cuanto subincluidos, que no dispondrán de acceso a los derechos, mecanismos y garantías jurídicas, porque carecen de las condiciones para realizarlos, aunque permanezcan rigurosamente subordinados a los deberes, responsabilidades y sanciones. Para los subincluidos, los derechos fundamentales del constitucionalismo no juegan un rol relevante en sus mundos de vida ${ }^{63}$. En tanto, los sobreintegrados o sobreincluidos tienen acceso a los derechos (y con ello, a los mecanismos y garantías jurídicas), sin vincularse efectivamente a los deberes y responsabilidades impuestas por el sistema jurídico ${ }^{64}$. Esto produce, en conjunto con otros esquemas de exclusión similares, una debilidad estructural de la ciudadanía como mecanismo político-jurídico de inclusión social.

Las consecuencias de lo anterior, para el orden constitucional, consisten en que la política fundada por dicho orden contará con una capacidad limitada de legitimidad, debido a la restricción en el acceso efectivo a la esfera pública que provoca la exclusión. Siguiendo la reflexión general de Neves ${ }^{65}$, esa limitación dificultará que la política esté en condiciones para la intermediación del disenso y el conflicto mediante los procedimientos democráticos, y que carezca de la apertura suficiente en los procedimientos de producción jurídica de decisiones colectivas vinculantes para la consideración y absorción de todos los intereses y valores del presente y el futuro de la sociedad. La política simplemente tendrá dificultades para resolver los conflictos relacionados con la exclusión étnica mediante sus procedimientos institucionales y se refugiará en sus operaciones procedimentales desconociendo o negando el conflicto, lo que se traducirá siempre en la represión de su emergencia ${ }^{66}$. Por cierto, la exclusión también debilita al derecho, en cuanto el sistema jurídico queda expuesto a su determinación por la influencia externa de los poderes sociales de los sobreincluidos, debilitándose sus procesos de autogeneración normativa y de aplicación del derecho vinculada solo al derecho preexistente; en tanto, sus reglas, principios y procedimientos perderán legitimidad entre los subincluidos.

La falta de inclusión por medio de la ciudadanía también tiene por consecuencia problemas de reconocimiento en la interacción cotidiana de los sujetos. El problema de la negación del reconocimiento en la interacción se produce precisamente cuando uno de los dos polos en la relación social recíproca entre un ego y un alter, no está dispuesto a soportar la libertad del otro, tanto porque no considera su comportamiento como acción -porque puede ser diferente del comportamiento esperado por ego-, como porque no toma en serio su perspectiva ${ }^{67}$. Una de las partes de la relación social no considerará a la otra persona en toda la dimensión que exige el discurso del constitucionalismo, expandiendo la desconfianza y dificultando con ello la cooperación. Por otra parte, la falta de reconocimiento, cuando este es amplio o generalizado, reforzará la exclusión

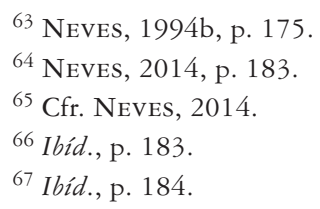


de personas y los grupos a que pertenecen, en este caso, los pueblos indígenas, en los sistemas funcionales de la sociedad. De esta manera, la exclusión en la subciudadanía de los indígenas, produce más exclusión en un círculo vicioso, por sus efectos en el no reconocimiento recíproco de todos los sujetos que integran la comunidad política. Esto redundará en evitar aún más "la construcción y desarrollo de una esfera pública 'universalista', indispensable para la concretización y realización de la Constitución del Estado democrático de derecho" 68 .

\section{LOS DERECHOS COLECTIVOS COMO ARTEFACTOS} DE INCLUSIÓN MEDIANTE EL ACOMODO CONSTITUCIONAL

Desde 2007, los derechos de los pueblos indígenas forman parte del derecho internacional consuetudinario ${ }^{69}$, con la adopción por la Asamblea General de las Naciones Unidas de la Declaración de Derechos de los Pueblos Indígenas, desarrollando derechos colectivos que estaban formulados en el Convenio 169 de la OIT de 1989, e incorporando otros. La Declaración reconoce el derecho a la autodeterminación, el derecho a la autonomía, a la participación, el derecho a practicar y mantener sus propias tradiciones culturales y espirituales, derechos a las tierras y recursos a los que estaban vinculados tradicionalmente, dentro de otros. Estos derechos son muy similares en los contenidos en la Declaración Americana sobre los Derechos de los Pueblos Indígenas, aprobada en 2016.

La elaboración de las declaraciones fue un proceso acompañado por el desarrollo de nuevas constituciones en América Latina, desde la década de los ochenta del siglo XX que comenzaron a tomarse en serio la "cuestión indígena" ${ }^{70}$. En ese período aparece un constitucionalismo pluralista ${ }^{71}$, caracterizado por la introducción de la diferencia étnico-cultural, con diversa profundidad, pero dentro de casi todos los ordenamientos constitucionales latinoamericanos.

El desarrollo que dicho constitucionalismo tiene en común con el desarrollo del derecho internacional de los derechos humanos de los pueblos indígenas la garantía de derechos colectivos cuya titularidad corresponderá a los pueblos indígenas.

Los derechos fundamentales colectivos son derechos que no son transferibles o reductibles a derechos individuales. Estos derechos son atribuidos por normas internacionales y las constituciones pluralistas a los pueblos indígenas como sujetos colectivos. Sin embargo, el carácter colectivo de aquellos derechos no deriva de sus condiciones de ejercicio, sino que más bien se refieren al sujeto al que se atribuyen -los pueblos indígenas como actores colectivos-y al objeto que protegen -bienes jurídicos colectivos en condiciones de vulnerabilidad ${ }^{72}-$. En cuanto a su ejercicio, las técnicas de operación de

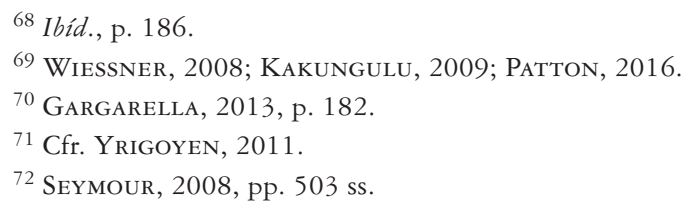


estos derechos varían desde el ejercicio por el sujeto comunitario titular en procesos de decisión colectiva, su ejercicio por medio de individuos representativos o su ejercicio por cualquier sujeto individual perteneciente a los pueblos indígenas.

Sobre la base de la clasificación que hizo David Ingram ${ }^{73}$, podemos distinguir tres tipos de derechos colectivos: i) derechos que permiten a los miembros de grupos desfavorecidos o marginados integrarse a la sociedad mayor, y que están destinados a ser temporales y remediales, orientándose a garantizar la igualdad de trato para todos; ii) derechos a exenciones y otros arreglos basados en la religión, espiritualidad o la conciencia moral, que permiten a los miembros de grupos practicar y desarrollar libremente sus creencias; y iii) derechos colectivos de índole política, destinados a compartir el poder político estatal con los grupos titulares de derechos.

Precisamente este tercer tipo de derechos colectivos atribuidos a los pueblos indígenas pretende tener la mayor incidencia para modificar la configuración de los Estados que concebían a sus comunidades políticas como monoculturales. Estos derechos buscan una reconceptualización de los pueblos indígenas como sujetos políticos preexistentes, anteriores y con dignidad equivalente a la nación construida por el Estado. El fundamento de todos esos derechos es el derecho a la autodeterminación, es decir, el derecho de los pueblos indígenas a determinar su propio estatus político y perseguir libremente su desarrollo económico, social y cultural. Para Michel Seymour, la protección de la autodeterminación de pueblos subalternos se funda, antes que en su singularidad cultural, en su identidad institucional, es decir, en que posee instituciones propias que subsisten total o parcialmente a su subordinación al Estado, pues solo los intereses que están relacionados con la protección, desarrollo y emancipación de esas identidades institucionales pueden pretender la protección mediante derechos ${ }^{74}$. Ahora bien, la autodeterminación de los pueblos indígenas se desenvolverá al interior de un Estado y se expresará en diversas formas de participación asegurada en el poder político estatal que permitan a los pueblos la determinación de su estatus político y de los caminos de su propio desarrollo en todos los ámbitos sin compulsiones externas ${ }^{75}$, pero que, a diferencia de la autodeterminación externa, no facultará a la autoorganización de un pueblo como Estado y la secesión respecto del Estado con que se relacionan.

La incorporación de derechos colectivos de índole política para los pueblos indígenas en los sistemas constitucionales, corresponden a una estrategia de tratamiento de las diferencias étnico-nacionales mediante la acomodación de ellas, en sustitución de las estrategias de asimilación. La acomodación constitucional procura una inclusión de las minorías y grupos étnicos no dominantes, en condiciones en que pueden seguir siendo distintas del grupo dominante y mantener sus propias características culturales

\footnotetext{
${ }^{73}$ Cfr. Ingram, 2011.

${ }^{74}$ Seymour, 2014, pp. 473 ss.

75 Cassidy, 1991, p. 1.
} 
libremente en una relación de reconocimiento recíproco, igualdad y coexistencia pacífica dentro del Estado ${ }^{76}$.

Los ordenamientos constitucionales que reconocen la autodeterminación interna de los pueblos indígenas o sus derivados (los derechos de autonomía, representación política especial, pluralismo jurídico, entre otros), establecen arreglos constitucionales que renuncian a reducir o denegar las diferencias étnico-culturales y, en lugar de ello, buscan establecer formas de acomodo entre la nación hegemónica que conducía el Estado y los pueblos que habían sido subalternizados.

Diversos mecanismos de acomodo constitucional han florecido globalmente en las últimas décadas y se expresan en formas de federalismo basadas en factores étnicos, y en especial para los pueblos indígenas en América Latina y otras regiones del mundo, acuerdos de autogobierno territorial y funcional dentro de Estados unitarios o federales, múltiples esquemas de representación política especial como cuotas o escaños dedicados, reconocimiento de esferas de validez para los sistemas normativos indígenas, además de reconocimiento de derechos territoriales, derechos de control sobre los recursos naturales, derechos culturales y lingüísticos ${ }^{77}$.

Los acomodos constitucionales que encarnan la autodeterminación interna reflejan una visión del liberalismo constitucional, en el que este puede ser suficientemente flexible como para permitir el desarrollo de artefactos constitucionales de inclusión -los derechos colectivos políticos-, que son específicos para tratar las diferencias étnicoculturales, reconociendo y garantizando una pluralidad de comunidades políticas dentro de la gran comunidad del Estado ${ }^{78}$. Stephen Tierney ha concebido cinco principios complementarios que nos permiten comprender cómo orientar los acomodos constitucionales de las diferencias étnico-culturales de una manera simétrica: i) el principio de autodeterminación, ya referido; ii) el principio de representación para asegurar que los pueblos subalternos tengan influencia en las decisiones estatales; iii) el principio de reconocimiento, en donde la pluralidad del Estado debe reflejarse en la cotidianidad de su vida en común y sus símbolos; iv) el principio de reciprocidad, por el que tanto las identidades históricamente hegemónicas como las identidades colectivas se reconocen como iguales entre sí y se comprometen a cooperar en un esfuerzo común dentro del Estado; y v) el principio de la democracia, en virtud del cual, los acomodos constitucionales y su desarrollo deben ser determinados dentro de las identidades colectivas por los sujetos individuales que pertenecen a ellas por medio de formas democráticas de deliberación y decisión colectivas.

Los mecanismos de acomodo constitucional generan una mayor complejidad interna de los sistemas jurídicos, la que puede fortalecer el pluralismo constitucional al positivar nuevas instituciones jurídicas de mancomunidad entre los pueblos indígenas y el Estado (como los mecanismos de consulta y consentimiento previo indígena o formas de

\footnotetext{
76 MCGarry y O'Leary, 1993.

77 Ver Aguilar et al., 2011.

78 Tierney, 2004, p. 125 ss.
} 
representación política especial) y también hacer un lugar en el derecho positivo estatal a las instituciones propias de los pueblos indígenas (sistemas normativos y jurisdicciones indígenas, formas de autogobierno).

La mentalidad kantiana del constitucionalismo ha visto una transformación en los repertorios del liberalismo político constitucional ${ }^{79}$. El liberalismo clásico, universalista y neutral ante las diferencias étnicas, reducidas a la privacidad, estaba comprometido con la construcción de la nación cívica como dispositivo de igualación de todos los obligados y de generación de la voluntad de la soberanía popular. El momento crítico del comunitarismo instalará desde los setenta el multiculturalismo como una visión que cuestionaba la posibilidad de autonomía individual desarraigada y planteará la necesidad de proteger a las comunidades e identidades colectivas como contextos necesarios de una autonomía embebida en los vínculos sociales. Al momento comunitarista sucederán diversos intentos de formular el multiculturalismo dentro del liberalismo, en el entendido que los grupos étnicos deseaban antes incrementar su reconocimiento como libres e iguales dentro de la vida estatal, que hacer un cuestionamiento profundo de la modernidad política. Las conocidas propuestas de Josep Raz, Will Kymlicka, Alan Patten, han sostenido, con variaciones, que hay intereses apremiantes relacionados con la pertenencia cultural y la identidad que son compatibles con los principios liberales y que justifican la adopción de medidas para fomentar la prosperidad cultural y material de los grupos culturales y respetando su identidad ${ }^{80}$. Los aportes del republicanismo han cuestionado la visión estática y no dialógica de las identidades culturales, en tanto las críticas poscolonial y decolonial han tematizado el valor de inclusión del concepto de nación, aún en su dimensión más cívico-institucional, poniéndonos ante un escenario de pluralismo nacional.

Los derechos colectivos indígenas se han transformados en dispositivos centrales para la inclusión constitucional que buscan modificar la subinclusión de los pueblos indígenas y que apuestan a trascender la negativa "constitucionalización simbólica" en que estaba atrapado el lenguaje constitucional clásico por medio de la negación de las identidades institucionales de los pueblos indígenas. Se trata de lograr que los pueblos indígenas sean parte efectiva de la vida colectiva del Estado, simbólica y materialmente, que sean tratados como partícipes activos de la comunicación política del Estado constitucional.

Sin embargo, en dicha pretensión inclusiva, lo decisivo de aquellos derechos colectivos es la capacidad real que tengan para abrir el sistema político a los intereses y valores indígenas, logrando alcanzar una influencia en todas las decisiones colectivas que puedan ser relevantes para su inclusión. Los riesgos para ello que surgen en el funcionamiento real de los ordenamientos constitucionales pueden ser de diversa índole: i) que los asuntos indígenas se mantengan encapsulados en aquellas instituciones sin poder expandirse al resto del orden constitucional; ii) que las contradicciones de las instituciones de acomodo constitucional con otras instituciones del sistema jurídico no

\footnotetext{
79 Cfr. Patten, 2016.

${ }^{80}$ KymlickA, 2003, p. 56.
} 
sean resueltas reconociendo su primacía constitucional, o bien estableciendo un adecuado balance con el resto de las instituciones constitucionales; iii) que el poder político transforme en alguna medida a los derechos de los pueblos indígenas en nuevos dispositivos simbólicos en sentido negativo, quedando sin la suficiente concreción normativa, en tanto son afirmados ideológicamente como señales de una mejora en la inclusión de los pueblos indígenas; iv) que la práctica de los derechos colectivos los contrapongan a la realización de los derechos individuales de los individuos que pertenecen a los pueblos indígenas, reduciendo así su capacidad inclusiva.

Si bien lo anterior solo puede ser corroborado empíricamente, se requieren cambios más profundos en la cultura constitucional que la simple positivización de instituciones de acomodo constitucional, cambios que requerirán diversos tiempos de consolidación y estabilización. La consagración de derechos colectivos para los pueblos indígenas, en lugar de resolver por sí solos la subinclusión constitucional de estos, instalan campos de fuerzas de la vida práctica del derecho y la política que podrían permitir observar, evaluar, deliberar y cambiar progresivamente las barreras de inclusión para esos pueblos. Esto no tendrá una naturaleza muy diferente de la larga evolución que significó hacer efectivo el poder del voto universal o la incorporación de las mujeres a la vida pública, pero con un énfasis mucho más claro en los vínculos entre los avances del derecho internacional y los avances del derecho constitucional doméstico para desenvolver esa tarea.

\section{Conclusión}

La sociología del derecho nos permite concebir cómo las constituciones sirven en la práctica social para construir simultáneamente un sistema político plural, institucionalizado, abstracto y abierto a la complejidad social, así como un sistema jurídico autogenerativo, inclusivo y capaz de variación frente a los cambios de la sociedad.

Desde la teoría de sistemas sociales de Luhmann, así como de las visiones de Rudolf Smend y Hauke Brunkhorst, se destaca la pretensión inclusiva del constitucionalismo. Las constituciones buscan hacer posible la inclusión social mediante la organización pública del poder, la democracia y los derechos fundamentales. El constitucionalismo se hace indisociable de la inclusión, tanto en sus efectos en la sociedad como en los discursos de la mentalidad constitucional en los Estados modernos, que defiende la copertenencia de la autonomía individual y la autodeterminación democrática. Esas promesas de libertad igualitaria construyen la fuerza discursiva inclusiva del constitucionalismo moderno.

Sin embargo, dichas promesas de inclusión chocan con la constante realidad de la subinclusión de los pueblos indígenas. En la construcción constitucional de los Estados, dichos pueblos fueron negados y privados de sus recursos, quedando en una situación enmascarada por un constitucionalismo meramente simbólico y negativo. Esta negación comienza en el momento constitucional de la organización de los Estados poscoloniales, pero se mantiene en el desarrollo republicano de ellos, en cuanto los pueblos indígenas no serán parte activa de la vida pública del Estado constitucional. 
En las transformaciones de las tendencias constitucionales de las últimas décadas, los derechos colectivos, y en especial la autodeterminación interna de los pueblos indígenas, procuran servir de dispositivos inclusivos para corregir su subinclusión constitucional. Las capacidades inclusivas de estos mecanismos de acomodo constitucional dependerán de un cambio de las prácticas y discursos del constitucionalismo que van más allá de su positivización normativa.

\section{BIBLIOGRAFÍA}

Aguilar, G.; Lafosse, S.; Rojas, H.; STEward, R., 2011: Justicia constitucional y modelos de reconocimiento de los pueblos indígenas, México: Editorial Porrúa.

Baraldi, C.; Corsi, G.; Esposito, E., 1997: GLU: Glossar zu Niklas Luhmanns Theorie sozialer Systeme, Frankfurt am Main: Suhrkamp Verlag.

Barre, Marie, 1988: Ideologías indigenistas y movimientos indios, México: Siglo Veintiuno.

BengoA, José, 1995: "Los indígenas y el estado nacional en América Latina", Revista de Antropología, USP, Vol. 38, $\mathrm{N}^{\circ}$ 2. Disponible en http://www.journals.usp.br/ra/article/ viewFile/111563/109649 [Fecha de consulta: 23.08.2017].

Biaggini, Giovanni, 2003: "La idea de Constitución: ¿Nueva orientación en la época de la globalización?", Anuario Iberoamericano de Justicia Constitucional, No 7 . Disponible en https:// recyt.fecyt.es/index.php/AIJC/article/view/50667/30886 [Fecha de consulta: 24.08.2017].

BRUNKHORST, Hauke, 2014: Critical Theory of Legal Revolutions: Evolutionary Perspectives, London: Bloomsbury.

Bonfil Batalla, Guillermo, 1970: "Del indigenismo de la revolución a la antropología crítica”, en Arturo Warman et al. (editores), De eso que llaman la antropología mexicana, México, Editorial Nuestro Tiempo, pp. 39-65.

Carmagnani, Marcello, 1984: Estado y Sociedad en América Latina 1850/1930, México: Grijalbo.

CARré De MAlberg, Raymond, 1962: Contribution à la théorie générale de l'Etat spécialement d'après les données fournies par le droit constitutionnel, Paris: Editions du CNRS.

CAssidy, Frank, 1991: "Selfdetermination, sovereignty, and selfgovernment", en Frank Cassidy, (editor), Aboriginal selfdetermination, proceedings of a conference, Lantzville, BC \& Halifax: Oolichan Books and the Institute for Research on Public Policy, pp. 1-14.

Castillo Vegas, Jesús, 2013: "El estatuto jurídico de los indígenas en las constituciones hispanoamericanas del período de la emancipación”, Revista de Estudios Históricos-Juridicos, $\mathrm{N}^{\circ}$ 35. Disponible en http://www.scielo.cl/scielo.php?script=sci_arttext\&pid=S071654552013000100013\&lng =es\&nrm=iso\&tlng=es [Fecha de consulta: 22.08.2017].

Clavero, Bartolomé, 1994: Derecho Indígena y Cultura Constitucional en América, México: Siglo XXI Editores.

Clavero, Bartolomé, 2016: Constitucionalismo Latinoamericano: Estados Criollos entre Pueblos Indígenas y Derechos Humanos, Santiago de Chile: Ediciones Olejnik.

De Georgi, Raffaele, 1998: Direito, democracia e risco: vínculos com o futuro, Sao Paulo: Sergio Antonio Fabris Editor.

Estermann, Josef, 2014: "Colonialidad, descolonización e interculturalidad: Apuntes desde la Filosofía Intercultural”, Polis, Vol. 13, No 38. Disponible en http://www.redalyc.org/ articulo.oa? id=30531773016 [Fecha de consulta: 22.08.2017].

Galligan, Denis y Versteeg, Mila, 2013: "Social and political foundations of Constitutions", en Denis Galligan (editora), Social and political foundations of Constitutions, Oxford: Cambridge University Press, pp. 3-48. 
García, José María, 2012: "La Exclusión Social en la Teoría Social de Niklas Luhmann”, Século XXI - Revista de Ciências Sociais, Vol. 2, No 1. Disponible en http://www.pensamientocritico. org/josgar0514.pdf [Fecha de consulta: 15.08.2018].

Gargarella, Roberto, 2013: Latin American constitutionalism, 1810-2010: the engine room of the Constitution, Oxford: Oxford University Press.

Giraudo, Laura; SANCHEZ, Juan-Martín, 2011: "Introducción: acotando el indigenismo en su historia”, en Laura Giraudo y Juan-Martín Sanchez (editores), La ambivalente historia del indigenismo: campo interamericano y trayectorias nacionales, 1940-1970, Lima: Instituto de Estudios Peruanos, pp. 9-19.

Grimm, Dieter, 2016: Constitutionalism: Past, Present, and Future, Oxford: Oxford University Press. Grupo de Barbados, 1979: Indianidad y descolonización en América Latina, Documentos de la Segunda Reunión de Barbados, México: Editorial Nueva Imagen.

Ingram, David, 2011: "Group Rights: A Defense”, en Thomas Cushing (editor), Handbook of Human Rights, New York: Routledge, pp. 277-298. Disponible en http://ecommons.luc. edu/philosophy_facpubs/15/ [Fecha de consulta: 22.08.2017].

Kakungulu, Ronald, 2009: The United Nations Declaration on the Rights of Indigenous Peoples: a new dawn for indigenous peoples' rights? Cornell Law School, Inter-University Graduate Student Conference Papers. Disponible en http://scholarship.law.cornell.edu/lps_clacp/18/ [Fecha de consulta: 21.08.2017].

Koenig, Matthias y De GuChteneire, Paul, 2007: "Political Governance of Cultural Diversity", en Matthias Koenig y Paul De GuChteneire (editores), Democracy and Human Rights in Multicultural Societies, París: Unesco, pp. 3-17. Disponible en https://politicaedireitoshumanos. files.wordpress.com/2011/09/democracy_and_human_rights_in_multicultural_societies_intro1.pdf [Fecha de consulta: 03.09.2017].

Koskenniemi, Martti, 2007: "Constitutionalism as mindset: Reflections on Kantian themes about international law and globalization", Theoretical Inquiries in Law, Vol. 8, $\mathrm{N}^{\circ} 1$. Disponible en http://www7.tau.ac.il/ojs/index.php/til/article/viewFile/608/571 [Fecha de consulta: 10.09.2017].

Kymlicka, Will, 2003: "Liberal Theories of Multiculturalism”, en Lukas Meyer et al. (editores), Rights, Cultures, and the Law, Oxford: Oxford University Press, pp. 229-250.

LeVaggi, Abelardo, 2001: "República de indios y república de españoles en los reinos de Indias", Revista de Estudios Histórico-Jurídicos, $\mathrm{N}^{\circ} 23$. Disponible en http://www.scielo.cl/scielo. php?script=sci_arttext\&pid=S0716-54552001002300009 [Fecha de consulta: 05.09.2017].

Luhmann, Niklas, 1965: Grundrechte als Institution, Berlin: Duncker \& Humblot.

LuHMann, Niklas, 1990: "Verfassung als evolutionäre Errungenschaft", Rechtshistorisches Journal, Vol. 9, $\mathrm{N}^{\circ} 1$.

Luhmann, Niklas, 1993: Das Recht der Gesellschaft, Frankfurt am Main: Suhrkamp Verlag.

LuHmann, Niklas, 1995: "Inklusion und Exklusion”, en Niklas Luhmann, Soziologische Aufklärung 6, Die Soziologie und der Mensch, Opladen: Westdeuscher Verlag, pp. 237-264.

Luhmann, Niklas, 2000: Die Politik der Gesellschaft, Frankfurt am Main: Suhrkamp Verlag.

McGarry, John y O'Leary, Brendan, 1993: "Introduction: The Macro Political Regulation of Ethnic Conflict”, en John McGarry y Brendan O'Leary (editores), The Politics of Ethnic Conflict Regulation, Abingdon: Routledge, pp. 1-40.

McIlwain, Charles Howard, 1947: Constitutionalism, Ancient and Modern, Ithaca: Cornell University Press.

ManN, Michael, 2007: "El Poder Autónomo del Estado: sus orígenes, mecanismos y resultados", Relaciones Internacionales, $\mathrm{N}^{\circ} 5$. Disponible en http://www.relacionesinternacionales.info/ojs/ article/view/49.html [Fecha de consulta: 05.09.2017]. 
Morlok, Martin, 2014: Soziologie der Verfassung, Tübingen: Mohr Siebeck.

Neves, Marcelo, 1994: A Constitucionalizaçâo Simbolica, Sao Paulo: Académica.

Neves, Marcelo, 1994b: "Del pluralismo jurídico a la miscelánea social: el problema de la falta de identidad de la(s) esfera(s) de juridicidad en la modernidad periférica y sus implicaciones en América Latina", El Otro Derecho $\mathrm{N}^{\circ} 6$.

Neves, Marcelo, 2014: "La Constitución y la esfera pública: entre diferenciación sistémica, inclusión y reconocimiento", Doxa, Cuadernos de Filosofía del Derecho, $\mathrm{N}^{\circ} 37$. Disponible en https:// doxa.ua.es/article/view/2014-n37-la-constitucion-y-la-esfera-publica-entre-diferenciacionsistemica-inclusion-y-reconocimiento [Fecha de consulta: 05.09.2017].

Patton, Paul, 2016: "Philosophical justifications for indigenous rights", en Damian Short, y Corinne Lennox (editores), Handbook of Indigenous Peoples' Rights, London: Routledge, pp. 13-23.

QuijadA, Mónica, 2007: "Estado nacional y pueblos originarios, entre la homogenización y la diversidad: ¿una pulsión colectiva duradera?”, en Laura Giraudo (coordinadora), Ciudadanía y derechos indígenas en América Latina: poblaciones, estados y orden internacional, Madrid: Centro de Estudios Políticos y Constitucionales, pp. 59-82.

Rosenfeld, Michel, 1994: "Modern Constitutionalism as Interplay between Identity and Diversity”, en Michel Rosenfeld (editor), Constitutionalism, Identity, Difference, and Legitimacy, Theoretical Perspectives. Durham y London: Duke University Press, pp. 3-35.

SANTos, Francisco y Amezúa, Luis, 2013: "El multiculturalismo y los derechos colectivos en el primer constitucionalismo iberoamericano", Revista de Derecho (Valparaíso), No 41. Disponible en http://www.scielo.cl/scielo.php?script=sci_arttext\&pid=S0718-68512013000200010 [Fecha de consulta: 04.09.2017].

Seymour, Michel, 2008: De la Tolérance à la Reconnaisance, Montreal: Boreal.

SEYmour, Michel, 2014: "Recognition, Politics of Difference, and the Institutional Identity of Peoples", en Avigail Eisenberg, A. et al. (editores.), Recognition Versus Self-Determination: Dilemmas of Emancipatory Politics, Vancouver: UBC Press, pp. 227-250.

SMEND, Rudolf, 1955: "Die politische Gewalt im Verfassungsstaat", en Smend, R., Staatsrechtliche Abhandlungen und andere Aufsätze, Berlin: Duncker \& Humblot, pp. 68-88.

Teubner, Gunther, 2011: "Verfassungen ohne Staat? Zur Konstitutionalisierung transnationaler Regimes", en Stefan Kadelbach y Klaus Günther (editores), Recht obne Staat? Zur Normativität nichtstaatlicher Rechtsetzung, Frankfurt am Main: Campus Verlag, pp. 49-100.

Thornhill, Chris, 2011: A Sociology of Constitutions: Constitutions and State Legitimacy in historicalsociological Perspective, New York: Cambridge University Press.

TIERnEY, Stephen, 2004: Constitutional law and national pluralism, Oxford: Oxford University Press.

Villoro, Luis, 1998: Los Grandes Momentos del Indigenismo en México, México: FCE.

Wiessner, Siegfried, "Indigenous sovereignty: A reassessment in light of the UN declaration on the rights of Indigenous Peoples", Vanderbilt Journal of Transnational Law, Vol, 41, 2008. Disponible en https://www.vanderbilt.edu/wp-content/uploads/sites/78/Wiessner_final_7. pdf [Fecha de consulta: 03.09.2017].

Yrigoyen, Raquel, 2011: "El horizonte del constitucionalismo pluralista: del multiculturalismo a la descolonización”, en César Rodríguez (editor), El Derecho en América Latina: un mapa para el pensamiento jurídico del siglo XXI, Buenos Aires: Siglo XXI Editores, pp. 139-159. 